\title{
Efektivitas Pemberian Aromaterapi Lavender Terhadap Intensitas Nyeri Post Sectio Caesarea
}

\author{
Gusti Ayu Tirtawati ${ }^{1}$,Atik Purwandari ${ }^{2}$, Nur Hidayah Yusuf ${ }^{3}$ \\ 1,2, 3 Jurusan Kebidanan Poltekkes Kemenkes Manado \\ Email : tirtagustiayu@gmail.com ; atikpurwandari75@yahoo.co.id ; yafs7711@gmail.com
}

\begin{abstract}
ABSTRAK
Latar Belakang : Sectio caesarea (SC) adalah suatu proses persalinan buatan yang dilakukan melalui pembedahan dengan cara melakukan insisi pada dinding perut dan dinding rahim ibu. Persalinan secara SC memberikan dampak bagi ibu dan bayi, nyeri yang hilang timbul akibat pembedahan pada dinding abdomen dan dinding rahim yang tidak hilang hanya dalam satu hari itu memberi dampak seperti mobilisasi terbatas, bounding attachment terganggu atau tidak terpenuhi.

Tujuan : Penelitian ini Untuk mengetahui efektivitas pemberian aromaterapi lavender terhadap intensitas nyeri post sectio caesarea

Metode : Penelitian ini adalah Quasi Experimental Design dengan rancangan Nonequivalent Control Group Design, Besarnya sampel dalam penelitian ini sebanyak 30 responden, kelompok kontrol sebanyak 15 responden dan kelompok intervensi sebanyak 15 responden, pengambilan sampel menggunakan tehnik Purposive Sampling, analisis data menggunakan uji One Way Anova.

Hasil : nilai rata-rata mean pada kelompok kontrol sebelum $=5,87$ dan sesudah $=5,67$, sedangkan pada kelompok intervensi sebelum $=5,87$, dan sesudah $=4.47$. Standar Deviasi pada kelompok kontrol sebelum $=1.187$ dan sesudah $=1.175$, sedangkan pada kelompok intervensi sebelum $=1.302$ dan sesudah $=1.457$. Hasil analisis statistik membuktikan bahwa terdapat perbedaan yang bermakna antara intensitas nyeri sebelum diberikan aromaterapi lavender dan setelah diberikan aromaterapi lavender, Kesimpulan : menghirup aromaterapi banyak memberikan manfaat baik secara lansung maupun tidak lansung, sebagai rekomendasi dalam intervensi terhadap intensitas nyeri pada post operasi.
\end{abstract}

Kata kunci: Post Sectio Caesarea, aromaterapi lavender, intensitas nyeri.

\begin{abstract}
Background: Sectio caesarea (SC) is an artificial labor process that is performed through surgery by making incisions in the abdominal wall and the uterine wall of the mother. Delivery by SC has an impact on both the mother and the baby, the pain that goes away from surgery on the abdominal wall and uterine wall that does not disappear in just one day have impacts such as limited mobilization, disturbed or unfulfilled bounding attachments.

Purpose: This study was to determine the effectiveness of lavender aromatherapy on the intensity of post sectio caesarean pain

Methods : This study is a Quasi-Experimental Design with Nonequivalent Control Group Design, the size of the sample in this study was 30 respondents, the control group was 15 respondents and the intervention group was 15 respondents, the sample was taken using purposive sampling technique, the data analysis used the One Way Anova test. .

Results: the mean value in the control group before $=5.87$ and after $=5.67$, while in the intervention group before $=5.87$, and after $=4.47$. Standard deviation in the control group before $=1.187$ and after $=1.175$, while in the intervention group before $=1.302$ and after $=1.457$. The results of the statistical analysis proved that there was a significant difference between the intensity of pain before being given lavender aromatherapy and after being given lavender aromatherapy.
\end{abstract}


Conclusion: Inhaling aromatherapy provides many benefits, both directly and indirectly, as a recommendation in interventions for postoperative pain intensity.

Keywords: Sectio Caesarea, lavender aromatherapy, pain intensity

\section{PENDAHULUAN}

Sectio caesarea (SC)adalah suatu proses persalinan buatan yang dilakukan melalui pembedahan dengan cara melakukan insisi pada dinding perut dan dinding rahim ibu. ${ }^{(\mathbf{1})}$ Tindakan operasi SC menyebabkan nyeri dan mengakibatkan terjadinya perubahan kontinuitas jaringan karena adanya pembedahan. Salah satu masalah yang akan ditimbulkan oleh nyeri tersebut adalah masalah laktasi. (2)

Nyeri yang timbul setelah dilakukan tindakan SC terjadi sebagai akibat adanya torehan jaringan yang mengakibatkan kontuinitas jaringan terputus dan stimulasi ujung saraf oleh bahan kimia yang dilepas pada saat operasi atau terjadinya iskemi jaringan akibat gangguan aliran darah ke salah satu bagian jaringan. ${ }^{(1)}$ Persalinan secara SC memberikan dampak bagi ibu dan bayi, nyeri yang hilang timbul akibat pembedahan pada dinding abdomen dan dinding rahim yang tidak hilang hanya dalam satu hari itu memberi dampak seperti mobilisasi terbatas, bounding attachment (ikatan kasih sayang) terganggu/tidak terpenuhi, Activity of Daily Living (ADL) terganggu pada ibu dan akibatnya nutrisi bayi berkurang sebab tertundanya pemberian ASI sejak awal, selain itu juga mempengaruhi Inisiasi Menyusui Dini (IMD) yang akan mempengaruhi daya tahan tubuh bayi yang dilahirkan secara sectio caesaria. ${ }^{(3)}$

Penanganan yang sering digunakan untuk menurunkan nyeri post sectio caesarea berupa penanganan farmokologi dan terapi non farmakologis. Salah satu terapi non farmokologi yang dapat digunakan adalah aromaterapi. Efek aromaterapi positif karena aroma yang segar dan harum merangsang sensori dan akhirnya mempengaruhi organ lainnya sehingga dapat menimbulkan efek yang kuat terhadap emosi. Aromaterapi ditangkap oleh reseptor dihidung, kemudian memberikan informasi lebih jauh karena diotak yang mengontrol emosi dan memori serta memberikan informasi ke hipotalamus yang merupakan pengatur sistem internal tubuh, sistem seksualitas, suhu tubuh, dan reaksi terhadap stress. ${ }^{(4)}$

Aromaterapi banyak dimanfaatkan sebagai pengobatan, khusunya penyembuhan beragam penyakit, meskipun aromaterapi ditujukan sebagai terapi pendukung (support therapy). ${ }^{(5)}$ Aromaterapilavender merupakan salah satu minyak yang paling aman sekaligus mempunyai daya antiseptik yang kuat, antivirus dan anti jamur serta dapat meringankan nyeri dan sakit kepala. Aromaterapi juga biasa digunakan pada linimen yang dipercaya mempercepat penyembuhan sel-sel kulit yang terbakar sinar matahari, terluka, dan rash.Karena banyak khasiatnya, minyak lavender merupakan salah satu minyak yang terpopuler dalam aromaterapi. ${ }^{(6)}$

Berdasarkan penelitian yang dilakukan pada ibu bersalin terbukti secara signifikan karena sebelum diberikan aromaterapi lavender mengalami nyeri berat dan setelah diberikan aromaterapi lavender ibu bersalin 
mengalami penurunan nyeri sedang, sehingga dapat dikatakan bahwa aromaterapi lavender sangat mempengaruhi penurunan nyeri persalinan kala 1 fase aktif. $^{(7)}$ Penelitian lain menunjukkan bahwa aromaterapi lavender juga mampu menurungkan nyeri luka perenium pada ibu post partum, dimana hasil menunjukkan adanya penurunan nyeri sebelum dan sesudah dilakukan inhalasi aromaterapi lavender. ${ }^{(8)}$

Data dari ruangan Instalasi Rawat Inap D Bawah RSUP. Prof. Dr. Kandou Manado pasien post sectio caesareaarea tahun 2015 sebanyak 624 orang (36\%). Pada tahun 2015 sebanyak 552 orang. Tahun 2016 sebanyak 494 orang (43\%), dan pada Tahun 2017 sebanyak 694 orang (53\%). Studi pendahuluan yang dilakukan di Irina D Bawah RSUP Prof DR. R. D Kandou Manado pada tanggal 9 Maret 2018 melalui wawancara kepada 10 pasien post SC, 7 pasien diantaranya menunjukkan skala nyeri berat dan 3 menunjukkan skala nyeri sedang. diantara 7 pasien tersebut yang mengalami nyeri berat mengatakan masih sulit untuk beradaptasi dengan nyeri dan berharap ada obat analgetik untuk dapat mengurangi nyeri yang dialaminya.

Berdasarkan fenomena tersebut diatas peneliti tertarik untuk melakukan penelitian tentang efektivitas pemberian aromaterapi lavender terhadap intensitas nyeri post sectio caesarea.

\section{METODE}

Penelitian ini merupakan jenis penelitian Quasi Experimental Design adalah penelitian yang di lakukan dengan memberikan percobaan atau perlakuan dengan menggunakan rancangan Nonequivalent Control Group Design yang artinya terdapat dua kelompok yang di gunakan untuk penelitian, yaitu kelompok eksperimen (yang di beri perlakuan) dan kelompok kontrol (yang tidak di beri perlakuan), dan tidak di pilih secara random. ${ }^{(9)}$ Penelitian ini dilakukan pada bulan Juli sampai Agustus 2018 di Irina D RSUP Prof. Dr. R. D Kandou Manado. Variabel bebas (Independent Variable) dalam penelitian ini adalah aromaterapi lavender dan Variabel terikat (Dependent Variable) dalam penelitian ini adalah intensitas nyeri. Populasi dalam penelitian ini adalah seluruh ibu post SC di Irina D RSUP Prof. Dr. R. D Kandou Manado. Besarnya sampel dalam penelitian ini yaitu penelitian eksperimen 30 sampel. Sampel kelompok intervensi sebanyak 15 responden dan kelompok control sebanyak 15 responden. Teknik yang digunakan dalam pengambilan sampel adalah tehnik Purposive Sampling yaitu pemilihan sampel dengan menetapkan subjek yang memenuhi kriteria penelitian sampai sampel terpenuhi. ${ }^{(\mathbf{1 0})}$ 


\section{HASIL}

Tabel 1. Distribusi responden berdasarkan umur, pendidikan, paritas, riwayat persalinan

\begin{tabular}{ccccc}
\hline \multicolumn{1}{c}{ Variabel } & \multicolumn{2}{c}{ Kontrol } & \multicolumn{2}{c}{ Intervensi } \\
\cline { 2 - 5 } & $\mathrm{n}$ & $\%$ & $\mathrm{n}$ & $\%$ \\
\hline Umur : & 2 & 13.3 & 2 & 13.3 \\
$<20$ & 10 & 66.7 & 8 & 53.3 \\
$20-35$ & 3 & 20 & 5 & 33.3 \\
$>35$ & 3 & & & \\
Pendidikan : & 6 & 40 & 5 & 33.3 \\
SMP & 6 & 40 & 7 & 46.7 \\
SMA/SMK & & 3 & 20 \\
D3/S1 & 8 & 53.3 & 6 & 40 \\
Paritas : & 7 & 46.7 & 9 & 60 \\
Primipara & & & & \\
Multipara & 7 & 46.7 & 7 & 46.7 \\
Riwayat Persalinan & 4 & 26.7 & 3 & 20 \\
Belum Pernah & 4 & 26.7 & 5 & 36.3 \\
Normal & & &
\end{tabular}

Dari tabel 1. Menjelaskan sebagian besar umur responden 20-35 tahun, pendidikan sebagian besar SMA/SMK, paritas sebagian besar multipara, serta riyawat persalinan sebagian besar belum pernah melahirkan.

Tabel 2. Perbedaan Intensitas nyeri sebelum dan sesudah diberikan aromaterapi lavender pada ibu post SC

\begin{tabular}{|c|c|c|c|c|c|}
\hline \multicolumn{2}{|c|}{ Kelompok } & Mean & $\mathrm{SD}$ & $F$ & $p$ \\
\hline \multirow{2}{*}{ Kontrol } & Sebelum & 5.87 & 1.187 & \multirow{4}{*}{4,115} & \multirow{4}{*}{0,010} \\
\hline & Sesudah & 5.67 & 1.175 & & \\
\hline \multirow{2}{*}{ Intervensi } & Sebelum & 5.87 & 1.302 & & \\
\hline & Sesudah & 4.47 & 1.457 & & \\
\hline
\end{tabular}

Dari tabel 2. Menjelaskan analisis data secara statistik membuktikan bahwa terdapat perbedaan yang bermakna antara intensitas nyeri sebelum diberikan aromaterapi lavender dan setelah diberikan aromaterapi lavender

\section{PEMBAHASAN}

Aromaterapi memiliki banyak manfaat, salah satunya adalah sebagai analgesik.
Sifat analgesik Aromaterapi bekerja karena sifat anti radang (anti inflamasi) efek pada peredaran darah (circulatory), menghilangkan racun (detoxifying) dan efek mati rasa (anstesptik). Aromaterapi yang bersifat analgesik adalah lavender, cengkih, chamomile frankincense, wintergreen dan mint. ${ }^{(6)}$ 
Berdasarkan hasil perhitungan menggunakan uji One Way Anova didapatkan hasil analisis data secara statistik membuktikan bahwa terdapat perbedaan yang bermakna antara intensitas nyeri sebelum diberikan aromaterapi lavender dan setelah diberikan aromaterapi lavender dengan nilai $\mathrm{F}=4,115$ dan $p$-value $=0,010$ ( $p$ value $=<0,05$. Hal ini disebabkan karena aromaterapi lavender mampu memberikan efek relaksasi dan menenangkan pikiran sehingga nyeri tersebut dapat berkurang.

Hasil penelitian ini didukung oleh beberapa penelitian. Pada penelitian yang dilakukan sebelumnya, mengenai efek aromaterapi pasca sectio caesarea menunjukkan bawa kisaran nyeri pada pasien post SC rata-rata 5,44 dan setelah dilakukan pemberian inhalasi aromaterapi lavender mengalami penurunan nyeri ratarata 4,33 dengan nilai $p=0,01(p<0,05)$. (11) Penelitian ini sejalan dengan penelitian tentang pemberian aromaterapi terhadap ibu bersalin kala I fase aktif menunjukkan bahwa sebagian besar sebelum diberikan aromaterapi lavender ibu bersalin mengalami nyeri berat dan setelah diberikan aromaterapi lavender ibu bersalin mengalami penurunan nyeri menjadi nyeri sedang. Dengan hasil uji statistik terdapat perbedaan yang signifikan antara tingkatan nyeri sebelum dan sesudah diberikan aromaterapi (nilai $p=0,01(p<0,05) .{ }^{(12)}$ Ini menunjukkan bahwa adanya efektifitas pemberian aromaterapi lavender terhadap penurunan tingkat nyeri pada ibu bersalin kala I fase aktif, sehingga penggunaan aromaterapi lavender pada ibu bersalin dapat direkomendasikan.

Efek lain yang dipengaruhi oleh pemberian aromaterapi adalah efek relaksasi. Selain dapat mengurangi nyeri dapat pula mengurangi kecemasan. Hal menarik yang ditemukan saat intervensi adalah ada salah satu responden yang umurnya 40 tahun yang dari hasil wawancara bahwa sebelumnya ibu melahirkan normal dan baru kali ini merasakan nyeri yang disertai pusing.Setelah dilakukan pemberian aromaterapi lavender ibu merasakan pusing itu menghilang dan merasa jauh lebih baik dari sebelum diberikan aromaterapi.

Penelitian sebelumnya tentang dampak lavender yang dihirup pada kecemasan dan nyeri yang disebabkan oleh pemasangan IUD mngalami penurunan setelah dilakukan intervensi dengan hasil penelitian tersebut adalah nilai signifikansi $p=0,01 \quad(p<0,05), \quad$ hasil penelitian menunjukkan bahwa terdapat pengurangan nyeri dan kecemasan setelah dilakukan inhalasi lavender. ${ }^{(\mathbf{1 3})}$ Menurut Gnatta, dkk (2016) aromaterapi adalah terapi kesehatan praktis atau komplementer yang menggunakan volatilekonsentrat diekstraksi dari tanaman yang disebut minyak esensial, untuk meningkatkan fisik, mentaldan kesejahteraan emosional. (14)

Penelitian tentang pengaruh aromaterapi lavender terhadap penurunan kecemasan pada ibu post SC. Hampir seluruhnya ibu pre operasi sectio caesarea mengalami kecemasan berat, namun setelah dilakukan pemberian intervensi aromaterapi lavender pada saat post test ibu mengalami penurunan kecemasan menjadi kecemasan sedang. sehingga dapat disimpulkan bahwa ada pengaruh Aromaterapi lavender terhadap penurunan kecemasan sebelum dan setelah dilakukan pemberian aromaterapi dengan hasil 
analisis ststistik menunjukkan $p$-value $=$ $0,000(<0,005) .(\mathbf{1 5})$

Aromaterapi memiliki banyak manfaat bagi kesehatan dan bisa dijadikan sebagai terapi alternative dalam beberapa masalah kesehatan.Selain aromaterapi lavender ada banyak aromaterapi yang bisa dijadikan sebagai terapi kesehatan selain aroma salah satunya yaitu aromaterapi clary (minyak clary).Temuan penelitian yang dilakukan tahun 2014 menunjukkan bahwa menghirup 5\% uap minyak clary efektif mengurangi stres yang terjadi selama pemeriksaan urodinamik pada pasien wanita dengan inkontinensia urin. Dengan demikian, menghirup 5\% minyak clary merupakan intervensi layak untuk mendorong relaksasi pada pasien yang menjalani pemeriksaan urodinamik. $^{(16)}$ Penelitian tahun 2014, mengatakan bahwa aromaterapi memiliki dampak signifikan dalam penurunan skor nyeri pasien terutama pada periode yang lebih lama. Bahkan ada berbagai faktor intervensi yang terkait dengan rasa sakit saat menjalani proses persalinan. Aromaterapi dapat menjadi terapi non-farmakologis yang pendekatan konklusif dalam membantu ibu sebelum dan setelah melahirkan. ${ }^{(17)}$

Pemberian aromaterapi lavender pada ibu post SC dapat mengurangi intensitas nyeri, sehingga aromaterapi lavender dapat dijadikan terapi alternativ non farmakologis dalam menangani permasalahan terkait dengan nyeri post SC ataupun masalah nyeri lainnya, juga mampu mengurangi kecemasan karena adanya efek relaksasi. Sejauh ini belum ada penelitian tentang efek samping aromaterapi terhadap tubuh karena aromaterapi 100\% mengandung essensial oil. Penelitian tahun 2016 menunjukkan bahwa aromaterapi lavender juga mampu menurungkan nyeri luka perenium pada ibu post partum. Hasil menunjukkan adanya penurunan nyeri luka perineum sebelum dan sesudah dilakukan inhalasi aromaterapi lavender sehingga penggunaan aromaterapi tersebut bisa dijadikan sebagai terapi komplementer. ${ }^{(8)}$

Masih banyak orang yang belum mengetahui manfaat dari aromaterapi. Sebagian masyarakat hanya beraanggapan bahwa aromaterapi hanya dijadikan sebagai alat pengharum ruangan ditempat-tempat tertentu. Salah satu contoh yang didapatkan dalam penelitian yaitu salah satu responden mengatakan bahwa saat menghirup aromaterapi, suasananya seperti halnya masuk ketempat spa atau di mall sehingga merasakan suasana tenang dan nyaman. Kita ketahui bahwa suasana tenang dan nyaman mampu meberikan perasaan senang sehingga beban atau rasa sakit yang mereka rasakan dapat berkurang.

\section{KESIMPULAN}

Intensitas nyeri luka operasi sebelum diberikan aromaterapi lavender, pada kelompok kontrol terbanyak pada skala nyeri sedang 11 responden $(73,3 \%)$ sedangkan pada kelompok intervensi nyeri sedang sebanyak 10 responden $(66,7 \%)$.

Intensitas nyeri luka operasi sesudah diberikan aromaterapi lavender, pada kelompok kontrol tidak mengalami perubahan yaitu skala nyeri sedang 11 responden $(73,3 \%)$ sedangkan pada kelompok intervensi menurun menjadi skala nyeri sedang 9 responden $(60 \%)$ dan nyeri berat sebanyak 5 responden (40\%).

Terdapat perbedaan yang bermakna antara intensitas nyeri sebelum diberikan aromaterapi lavender dan setelah diberikan aromaterapi lavender 


\section{SARAN}

Diharapkan persepsi masyarakat bisa berubah, bahwa masalah nyeri tidak harus dengan terapi farmakologis namun ada berbagai terapi non farmakologis yang bisa digunakan dalam mengatasi nyeri

\section{DAFTAR PUSTAKA}

1. Solehati, T dan Kosasih, E.C. (2015). Konsep Dan Aplikasi Relaksasi Dalam Keperawatan Maternitas. Bandung: Repika Aditama.

2. Pratiwi, R. (2012). Penurunan Intenstitas Nyeri Akibat Luka Post Seksio Sesarea setelah dilakukan Teknik Pernapasan. Student e-Journals. Vol. 1. No. 1. 2012.

3. Erina, S. dan Widia, L. (2016). Hubungan Antara Tekhnik Relaksasi Pernafasan Dalam Dengan Skala Nyeri Ibu Post Secti Caesarea 24 Jam Pertama di RSUD dr. H. Andi Abdurrahman Noor Tanah Bambu. Jurnal Darul Ashar Vol 1, No.1.

4. Wong. (2010). Easing anxiety with aromatherapy .http://altmedicine.about.com/od/anxiety/a/anxiety_acupuncture.htm. Diakses tanggal 26 Maret 2018. Jurnal online.

5. Jaelani. (2009). Aroma Terapi. Jakarta: Yayasan Pustaka Obor Indonesia.

6. Koensomardiyah. (2009). A-Z Aromaterapi Untuk Kesehatan, Kebugaran, dan Kecantikan. Yogyakarta: ANDI.

7. Turlina, L. (2017). Pengaruh Pemberian Aromaterapi Lavender terhadap Penurunan Tingkat Nyeri Pada Ibu Bersalin Kala I fase Aktif Di BPM Ny. Margelina.Jurnal Surya Vol. 09. No.01.

8. Windayani, W. (2016). Aromaterapi Layender dapat menurungkan Intensitas Nyeri Perineum pada Ibu Post Partum. Journal Ners and Midwifery Indonesia. JNKI, Vol 4, No.3 123-128.

9. Sugiyono. (2014). Metode Penelitian Pendidikan Pendekatan Kuantitatif Kualitatif dan R\&D. Bandung: Alfabeta.

10. Sulistyaningsih. (2011). Metodologi Penelitian Kebidanan Kuantitatif-Kualitatif. Yogyakarta: Graha Ilmu.

11. Dwijayanti, W., Sumarni, S., \& Ariyanti, I. (2013). Efek Aromaterapi Lavender Inhalasi Terhadap Intensitas Nyeri Pos Sectio Caesarea. Jurnal Medica Hospital Vol. 2 (2): 102-125.

12. Turlina, L. (2017). Pengaruh Pemberian Aromaterapi Lavender terhadap Penurunan Tingkat Nyeri Pada Ibu Bersalin Kala I fase Aktif Di BPM Ny. Margelina.Jurnal Surya Vol. 09. No.01.

13. Shahnazi1, M., Nikjoo, R., Yavarikia, P., Charandabi, A.M.S,. (2012). Inhaled Lavender Effect on Anxiety and Pain Caused From Intrauterine Device Insertion. Journal of Caring Sciences, 2012, 1(4), 255-261.

14. Gnatta, J.R., Kurebayashi, S.F.L., Turrini, T.N.R., dan Silva, D.P.J.M,. (2016). Aromatherapy and nursing: historical and theoretical conception. Jurnal of School of Nursing USP Revista Da Escolar de Enfermagem Da USP. Rev Esc Enferm USP · 2016;50(1):127-133.

15. Dila, R.D., Putra, F., dan Arifin, F.R,. (2017). Pengaruh Aromaterapi Lavender terhadap Penurunan Kecemasan Ibu Pre Operasi Sectio Caesarea di Rumah Sakit Bersalin.Caring Nursing Journal. Vol. 1 No. 2 (Oktober, 2017).

16. Seol, H.G., Lee, H.Y., Kang, P., You, H.Y., Park,M., and Min, S.S. (2013). Randomized Controlled Trial for Salvia sclarea or Lavandula angustifolia: Differential Effects on Blood Pressure in Female Patients with Urinary Incontinence Undergoing Urodynamic Examination. The Journal Of Alternative And Complementary Medicine. Volume 19, Number 7, 2013, pp. 664-670.

17. Amores, P.G. \& Cua, S.A. (2014). The Effectiveness of Aromatherapy in the Management of Postpartum Pain Among Patients Who Underwent Spontaneous Vaginal Delivery at a Tertiary Hospital. Jurnal Philippine Obstetrical and Gynecological Society (POGS) Research Paper Contest. Volume 38, Number 3, PJOG. 